\title{
SOBRE A FILOSOFIA NO BRASIL
}

\author{
Carlos Roberto Drawin *
}

DOMINGUES, Ivan. Filosofia no Brasil. Legados e Perspectivas. Ensaios metafilosóficos. São Paulo: Editora Unesp, 2017.

\footnotetext{
$\square$
} u não sou estudioso da área "Filosofia no Brasil" e meus interesses filosóficos vão em outra direção, embora tangenciem em alguns pontos aqueles desenvolvidos pelo professor Ivan Domingues no amplo espectro de suas atividades e pesquisas. Por que, então, escrever esta "nota bibliográfica" ao invés de deixá-la para alguém melhor preparado para a tarefa? $\mathrm{O}$ motivo imediato não há que se ocultar. $\mathrm{O}$ autor, além de meu colega por longos anos no Departamento de Filosofia da UFMG, é meu amigo e com ele convivi por anos ainda mais longos, desde nossa primeira juventude, quando éramos ainda estudantes. Ele no curso secundário, eu já iniciando os estudos universitários em Psicologia. Seria este um obstáculo para escrever esta "Nota"? Os afetos deveriam ser irremediavelmente expulsos do quefazer filosófico? Penso, em contrário, na impossibilidade e na inanidade de tal tarefa de depuração. Gostaríamos, talvez, tornar a filosofia um saber feito à imagem e semelhança daquelas ciências chamadas hard e, deste modo usufruir também o reconhecimento e o prestígio de que gozam numa época na qual a sua racionalidade parece ter se convertido em hegemônica. Assunto espinhoso, difícil de desenredar, aqui trazido, contudo, apenas a modo de recordar o ensinamento de Espinosa posto logo no início de seu Tratado Político: os filósofos concebem os afetos com que nos debatemos como vícios em que os homens incorrem por culpa própria. Por este motivo, costumam rir-se deles, chorá-los, censurá-los ou (os que que-

* Faculdade Jesuíta de Filosofia e Teologia, Belo Horizonte. 
rem parecer os mais santos) detestá-los. Creem, assim, fazer uma coisa divina e atingir o cume da sabedoria quando aprendem a louvar de múltiplos modos uma natureza humana que não existe em parte alguma e a fustigar com sentenças aquela que realmente existe. Com efeito, concebem os homens não como são, mas como gostariam que eles fossem. Destarte, queiramos ou não, os afetos estão aí, não apenas atravessando o rigor pretendido pelo discurso filosófico, mas nele sendo assumidos e dele fazendo parte. Esta nota é presidida por uma "paixão alegre", aquela de uma amizade longamente cultivada no respeito mútuo e, de minha parte, por uma admiração que só fez crescer no transcorrer do tempo.

Na comunidade acadêmica a carreira do professor Ivan Domingues é largamente conhecida: o percurso docente medido por várias décadas, o pesquisador eminente integrado ao $\mathrm{CNPq}$, o autor prolífico de tantos artigos e livros, o incansável trabalhador da academia em seu empenho na consolidação do Departamento de Filosofia da UFMG, onde foi um dos fundadores do Curso de Doutorado, o seu envolvimento na expansão e aperfeiçoamento da Comunidade Filosófica Brasileira. Tudo isto é bem sabido e encontrou o seu justo reconhecimento quanto da outorga do Prêmio FUNDEP de 2005, na área de Humanidades. Tudo isto é bem sabido e está formalmente registrado.

Não quero, contudo, deixar de lado algumas exigências do afeto, recordações do vivido e alguns poucos fragmentos anedóticos, ainda reverberantes, mas que vão desaparecendo na voragem do tempo. Por que não resgatá-los na oportunidade desta "Nota", agora a ser renomeada como "Biobibliográfica"? Comecemos pelo começo: o jovem modesto da pequena cidade de Pedro Leopoldo, nas cercanias da capital mineira, porém, apesar de sua proximidade, tão distante em seu provincianismo. Certamente era um ambiente pouco arejado, curto em ideias e com poucos interesses mais largos e voltados para o mundo, pois os olhares concentravam-se nas vidas alheias, ávidos de pequenos escândalos domésticos. Caracterização breve e também injusta, porque esquecida de tantos ricos encontros e bons amigos, tantos sonhos partilhados e conversas madrugada a dentro. Seja como for, da trama da vida puxo apenas um fio da memória. O fio e a trama de uma pequena história na qual se deu o meu encontro com o jovem Ivan, no ponto onde convergiam as nossas inquietações existenciais e políticas. Ele participava da JUPEL, um grupo católico de jovens com inclinação à esquerda, em sentimentos e atitudes idealistas e ingênuos, mas alentando uns aos outros da necessária esperança a nos sustentar naquele momento opressivo e funéreo da ditadura militar, então se encaminhando para os "anos de chumbo" posteriores ao Ato Institucional no 5 de dezembro de 1968. Ao nos encontrarmos eu trazia a aura de já ter sido preso e processado pela Lei de Segurança Nacional por minha participação no movimento estudantil. Como eu era militante de uma organização clandestina, a "Ação Popular", a minha aproximação ao grupo de jovens era também motivada 
pela missão de "ampliá-los", como se dizia então, ou seja, de "convertê-los" para um movimento que se pretendia revolucionário. Assim, imbuído do meu papel missionário, me aproximei como doutrinador daquele moço tímido, caladão, um pouco desconfiado e já cioso de seu entendimento das coisas, sem se deixar levar pelos meus ares de superioridade como estudante universitário e militante de esquerda aureolado pela prisão, com a pretensão de pontificar em meio a ingênuos secundaristas do interior. Deste recorte biográfico deve-se ressaltar este seu traço de caráter, pois ele iria se tornar uma das marcas de seu caminho: a obstinação no trabalho e o destemor em pensar por conta própria.

Nele já despontava o intelectual independente, embora já se orientando em direção ao marxismo. De minha parte, desconhecia inteiramente a obra de Marx e além de um ou outro texto de militância me respaldava inteiramente no "Documento de Base" da Ação Popular, de aceitação obrigatória para quem aderia ao movimento e no qual eu recolhia alguns elementos filosóficos compatíveis com minha visão cristã do mundo, embora a "organização", como aludíamos ao movimento com ares enigmáticos, já se definisse como marxista-leninista e optara pela violência revolucionária, a ser logo concretizada com a adesão à luta armada.

Da obra do Padre Henrique Vaz ouvira falar bastante superficialmente e o havia visto de relance apenas uma única vez. De qualquer modo a teoria era encarada com desconfiança e a primazia cabia sempre à prática, ao compromisso com a luta. O clima daqueles tempos é difícil de ser recuperado, o medo no presente e a esperança do futuro se misturavam numa enxurrada de certezas e de conviç̧ões dogmáticas. Mergulhado na agitação não pude perceber como o jovem Ivan avançava lentamente na seara bem mais prosaica dos estudos filosóficos. Agora, ao ler o seu livro, pude ver como ele reconstruiu com o distanciamento da história e a empatia de ricos depoimentos o papel do Padre Henrique Vaz como intelectual público e figura de aglutinação dos jovens católicos de esquerda, alguns deles, como Betinho, depois cantado como "irmão do Henfil", se tornaram nomes fortes na história política e social recente de nosso país, enquanto outros, como os professores Raul Landim Filho, Guido Antônio de Almeida, e Paulo Eduardo Arantes, desempenharam papel de destaque na formação da comunidade filosófica brasileira e no estabelecimento de parâmetros rigorosos para o pensamento.

Com o golpe civil e militar de 1964 e as tensões dele decorrentes o Padre Henrique Vaz teve de deixar a sua amada Faculdade Jesuíta de Filosofia de Nova Friburgo, na qual ele lecionava e refletia naquelas tardes de denso silêncio, apenas levemente cadenciado pelo passar das páginas dos grossos tratados escolásticos. Avesso às turbulências do mundo, mas sob a suspeição de ser um perigoso intelectual de esquerda, inspirador do "Documento de Base" da Ação Popular e malvisto por significativos segmentos da Igreja 
Católica, ele encontrou refúgio e generoso acolhimento no Departamento de Filosofia da Universidade Federal de Minas Gerais, dirigida naqueles dias pelo saudoso professor Arthur Versiani Velloso. Pôde, então, se entregar novamente ao seu intenso labor intelectual, explorando as terras inóspitas do "continente hegeliano" no qual, como dizia, o marxismo era apenas uma província rebelada. Por causa dessas vicissitudes políticas e eclesiais tivemos o privilégio de assistir às suas aulas magistrais. Ivan, ainda estudante de graduação, não era do seu círculo próximo, pois se voltara decididamente para os estudos marxianos sob a influência e orientação do nosso grande amigo comum, o professor Luiz de Carvalho Bicalho. Assim, Ivan e eu, nos íamos entrecruzando em nossas diferentes trajetórias: como colegas de curso, depois fazendo o mesmo concurso para professor, ele aprovado em segundo lugar e eu em terceiro, em seguida como colegas de magistério inicialmente no Ciclo Básico de Ciências Sociais onde compartilhávamos a mesma sala e a mesma indignação com os muitos arbítrios do regime militar. Porém, sem se perturbar, ele estudava com afinco, não só os autores do momento, os franceses, os Althussers e os Foucaults, mas para o meu espanto, debruçava sem alarde sobre os calhamaços, agora esquecidos no fundo das estantes: os Grundrisse, os "Fundamentos da crítica da economia política" e - pode-se ainda hoje imaginar? - destrinçava sem fraquejar a tediosa Die Agrarfrage, "A questão agrária" de Karl Kautsky. De sua inabalável determinação logo veio a colheita: a sua dissertação de mestrado, argüida pelo professor José Arthur Giannotti com uma brilhante, porém abstrusa exposição sobre o economista marxista italiano Piero Sraffa. Saímos para comemorar o sucesso da defesa e entre conversas, brincadeiras e chopes o professor Giannotti, impressionado com a seriedade do trabalho, the propôs o doutoramento na França. Em seu livro Ivan reúne o professor Giannotti, juntamente com o Padre Henrique Vaz e a professora Marilena Chauí no pequeno grupo dos "filósofos brasileiros intelectuais públicos", aqueles que preservaram a "concepção técnica da filosofia" e sem perder o rigor conceitual de suas obras "influenciaram o mundo da política". Talvez nestas figuras possamos encontrar certo movimento especular na vida do próprio autor, ele também apegado às razões do filósofo em abdicar, até certo ponto, das lutas políticas em sua exacerbação imediata, de modo a cultivar no distanciamento reflexivo o meio necessário e singular para pensar criticamente o mundo sem concessões aos modismos e partidarismos e sem, contudo, dele se alienar.

Na entrevista dada em 2016 para "Outramargem: revista de filosofia", editada pelos alunos da pós-graduação do Departamento de Filosofia, foram feitas algumas alusões ao doutorado na Sorbonne, à temporada francesa, à vivência do dépaysement, este sendo incorporado na fisionomia de sua vida intelectual e profissional, cujo caráter "desterritorializado" jamais foi obstáculo para a dedicação teimosa e o trabalho persistente, rotineiro e anônimo na expansão e aperfeiçoamento da filosofia no Brasil. 
Estas breves recordações nos servem como elementos de sinalização a mostrar que o livro em epígrafe nada tem de um trabalho circunstancial ou movido pelo afã da produtividade acadêmica. Ao contrário nele vemos entrelaçar a vida e a obra, as preocupações com os rumos do nosso país, já presentes naquelas inquietações de juventude, aqui pinçadas da memória, convergindo com o trabalho metódico que sem se deter no garimpo historiográfico se projeta em autêntica vocação filosófica. Não cabe nesta "Nota" a pretensão de resumir um livro de quase 600 páginas e menos ainda a vanidade de expor a originalidade de um argumento que somente a leitura direta do texto pode proporcionar. Todavia, podemos acenar ao possível leitor com o convite de uma leitura aprazível, proveitosa e instigante. Aprazível porque a leitura flui sem os escolhos das notas excessivas e rotineiramente impostas pela erudição acadêmica. Proveitosa porque o livro está muito bem estruturado, como se pode facilmente constatar acompanhando a antecipação sintética de seu conteúdo, tal como está apresentado no "Prefácio" (p. 1-16). A exposição, dividida em seis "passos", cobre todo desenvolvimento do pensamento filosófico brasileiro, desde seus primórdios coloniais, quando da transposição da escolástica, graças, sobretudo, ao sistema jesuítico de ensino (p. 141-205), até os últimos cinqüenta anos de sua vertiginosa expansão (p. 456-501) contendo até mesmo alguns dados do congresso da Anpof de 2014 (p. 461). Leitura instigante, qualidade a ser aqui ressaltada, justamente por expressar a abrangência e originalidade do projeto de pesquisa subjacente à feitura do livro.

Das seis etapas que organizam o percurso expositivo os quatro passos centrais seguem em sequência cronológica o desenvolvimento do pensamento filosófico brasileiro: o segundo passo, acerca do "passado colonial e seus legados" (p. 69-205); o terceiro passo, abarcando a "independência, império e república velha" (p. 207-332); o quarto passo, versando sobre "os anos 1930-1960 e a instauração do aparato institucional da filosofia" (p. 333-427); o quinto passo, focalizando "os últimos cinquenta anos" (p. 429-501). Aparentemente trata-se de um desdobramento linear no tempo narrando as vicissitudes da filosofia em nossas terras: a sua importação na época colonial, com objetivos primordialmente pedagógicos e apologéticos; a sua lenta implantação após a independência, no decurso do século XIX e do primeiro terço do século XX; a sua instauração institucional oriunda do processo de modernização desencadeado pela Revolução de 1930; a sua expansão e transformação qualitativa a partir da "grande virada dos anos 1969". Nada obstante, o fio cronológico, sendo o aspecto mais típico da historiografia filosófica, não é mero desenovelar de acontecimentos filosóficos, porque tece algumas figuras paradigmáticas do intelectual brasileiro e as insere no contexto mais amplo de nossa aventurosa história social. Nesta perspectiva, propõe para o período colonial o "intelectual orgânico da Igreja", tipificado pelo clérigo jesuíta comprometido com o 
apostolado intelectual e tendo como figura prototípica o padre Antônio Vieira. Após a expulsão dos jesuítas, no final da colônia e com o advento do império independente, emerge o "intelectual diletante estrangeirado" cuja manifestação exemplar encontra-se em Joaquim Nabuco, Sylvio Romero e Tobias Barreto, prócer filosófico da Escola do Recife A proclamação da república levou ao surgimento do "intelectual público republicano", dotado de perfil combativo, como se vê na campanha civilista de Ruy Barbosa e com o olhar não mais voltado para além-mar e sim dirigido ao interior do país e disposto a revolver as suas entranhas profundas, como se pode ver nos "sertões" de Euclides da Cunha. Após a Revolução de 1930, com a fundação da USP vai se impondo, no sulco metodológico aberto pela Missão Francesa, o "intelectual erudito", moldado na imagem do scholar concretizada na atividade dos "normaliens franceses" em sua presença uspiana. Este foi o ponto de impacto da modernização da filosofia a partir do qual se deu uma crescente irradiação para outros centros acadêmicos cuja expressão institucional se deu nos anos 1970 com o Sistema Nacional de Pós-Graduação (SNPG) protagonizado pela CAPES. Por isso não se pode isolar com facilidade uma ou outra figura típica, apenas indicar alguns nomes representativos de todo um grupo maior de estudiosos. Dentre eles são nomeados Guido de Almeida, Raul Landim, Oswaldo Porchat, Balthazar Barbosa Filho, Ernildo Stein e José Henrique Santos. (p. 8-12; p. 40-51).

Tal tipologia acima esboçada em rápidas pinceladas não se fixa em rigidez dogmática e avessa tanto à complexidade do mundo social, quanto à fluidez da história. O autor se esforça continuamente no trabalho de inserção da filosofia no quadro mais amplo de cada época, tal como reconstruída pelos historiadores e cientistas sociais. Deste modo, o sistema colonial é largamente descrito por meio do uso de alguns dados estatísticos, mas, sobretudo, de elucidativas hipóteses historiográficas, antropológicas, demográficas, políticas, geográficas e lingüísticas. (p. 69-141). O mesmo ocorrerá em todas as outras etapas do percurso cronológico, porém com destaque, em minha opinião, à instrutiva síntese econômica, social e política oferecida como enquadramento necessário para a compreensão das condições que impulsionaram a partir dos anos 1960 a transformação quantitativa e qualitativa da experiência filosófica brasileira. (p. 429-481). Ora, este jogo da construção de tipos ideais, "ajustando os elementos empíricos e os abstratos" (p. 53 e p. 435) entra numa certa tensão com os desafios oriundos da singularidade cultural e histórica da realidade brasileira. Acredito ser possível discernir esta tensão dialética na lenta constituição do "intelectual público republicado", "cuja tipificação se mostrou", como diz o autor, "especialmente complexa". (p.45). O olhar filosófico foi se deslocando no transcurso dos séculos, desde a colônia ao império, do exterior europeu para o interior de uma realidade não apenas dada ao olhar, mas também por ele constituída. Vê-se bem tal transição em Joaquim Nabuco, o homem público engajado na luta abolicionista e o intelectual anglicizante 
ou mesmo em Euclides da Cunha, engenheiro civil, jornalista e escritor de feição positivista e próximo da filosofia, viajando e investigando o Brasil profundo. A floração do intelectual público resultou deste cultivo difícil em terra por vezes pedregosa e graças aos esforços das gerações que se sucederam à lavratura jesuítica ainda na época colonial, passando pela sedução europeísta até chegar à especificidade de um ethos no qual convergem o rigor do pensamento e o compromisso político. Diversas alternativas então se abrem, cada uma delas assinalada pelo autor por uma personalidade filosófica contemporânea: Henrique de Lima Vaz, José Arthur Giannotti e Marilena Chauí (p. 485). Os três filósofos brasileiros, de alguma forma, representam caminhos que entrecruzaram com a trajetória do próprio autor e agora, até mesmo por sua maestria, encarnam opções fundamentais e realizações intelectuais que serão confrontadas com os desafios de uma civilização planetária. Estaria surgindo uma nova figura de filósofo, a do "intelectual cosmopolita globalizado"? Em qual horizonte ela se desenha e qual sentido anuncia? (p. 503-549).

Este tema instigante é tratado no último passo que compõe este rico painel da filosofia no Brasil (p. 503-549). Nele - quando as novas perspectivas são delineadas - "há uma espécie de inversão da estratégia analítica: o enjeu passa a ser a sondagem do futuro, na direção do inventário dos possíveis", tal opção impõe a prevalência dos aspectos conjecturais e especulativos e, por conseguinte, do "método in absentia", embora buscando o contraponto nas "positividades do presente" (p. 504). Os elementos empíricos e as descrições contextuais, sopesadas com os depoimentos de alguns dos nossos grandes scholars (Oswaldo Porchat, Raul Landim, Balthazar Barbosa, Guido de Almeida, Lima Vaz) buscam circunscrever tais positividades dentre as quais não se pode descartar a experiência do próprio autor na construção de sua equação pessoal ao entrelaçar a universalidade cosmopolita de suas indagações e a particularidade comprometida com o seu tempo histórico e o seu espaço cultural. Mesmo assim, a visão e as vivências do autor, os aspectos propriamente biográficos, não podem ser invocados em detrimento da consistência de seu argumento. A mobilização destes diversos recursos - dados, descrições, depoimentos, etc. - não deve obscurecer o arco conceptual que articula o primeiro e o último capítulos a explicitar o fio condutor filosófico que atravessa o conjunto da exposição. Pois a obra realizada não se enquadra inteiramente no domínio da historiografia filosófica, porque a intenção que a anima e a constitui em seu travamento interno é justamente "o argumento metafilosófico" como, aliás, já está devidamente registrado em seu segundo subtítulo. A discussão acerca da filosofia nacional, posta desde o início, revela o seu alcance no final, quanto o autor retomando a problemática de seu livro anterior, publicado em 2009 - "O continente e a ilha. Duas vias da filosofia contemporânea" - interroga acerca das "relações da filosofia com a história da filosofia" (p. 519). A primeira frase do prefácio, afirmando a continuidade 
entre as duas obras, reverbera nas últimas páginas quando são elencadas as diferentes maneiras de abordar o problema: o desprezo nietzscheano pela erudição excessiva, a "desconstrução" (Destruktion) heideggeriana da história da metafísica, a rememoração hegeliana da experiência dialética do pensamento. Seja como for, isto significaria que o olhar voltado para o passado interditaria a perscrutação do futuro?

A advertência hegeliana contra o profetismo não pode servir de álibi para calar as inquietações do presente e transformá-lo em burdo determinismo. Os "ensaios metafilosóficos" reunidos neste trabalho convergem na rejeição de uma filosofia acovardada, temerosa em pensar por medo de errar, escondida nos desvãos da especialização acadêmica. Por que não entrever no traçado virtual do intelectual cosmopolita globalizado algo em germinação na vida já vivida e, afinal, sempre revivescente? Por que não ver no "inventário dos possíveis" uma convocatória geracional? Um grito do sapere aude a nos despertar? Como um chamamento nosso, que somos multidão de anões, aprisionados no labor quotidiano das dissertações e traduções, teses e papers, de modo a estimular a expectativa da vinda do gigante. Quem sabe se o nosso Kant já nasceu ou está em vias de nascer em meio ao prosaísmo de nossas lides institucionais? Aqui Kant é menos o nome de um filósofo ou a expectativa do gigante vindouro a reiterar uma espécie de sebastianismo especulativo e muito mais o significante de nosso futuro civilizacional. Ou seríamos os eternos cativos de nosso autodesprezo, prontos a fixar o nosso atraso como fatalidade e curso inexorável das coisas? Alfredo Bosi numa pequena nota de trabalho intitulada "O mesmo e o diferente", tomando como sintomática epígrafe a lendária frase galileana do eppur si muove, questionou a razoabilidade de se tomar a contraposição "centro versus periferia", igual tantas outras do mesmo jaez, como dualidade estrutural, estática e definitivamente estabelecida. O eminente estudioso preferiu considerá-la como oposição dinâmica, condição passível de ser transformada. O livro do professor Ivan Domingues, no âmbito mais restrito da filosofia no Brasil, toma a mesma direção proposta por Alfredo Bosi ao investigar a passagem do paradigma da "formação" da filosofia brasileira para a época de sua "pós-formação" e na modelação ideal dos cinco tipos de intelectuais. Modelação proposta sem nunca esquecer a advertência weberiana acerca do caráter ideal dos tipos e sua relativa inadequação com relação à imensa complexidade e diversidade da realidade concreta. Por conseguinte, o autor não os apresenta como possibilidades abstratas e historicamente arbitrárias e sem, contudo, permitir que o caudal de suas leituras dissolva e disperse a armação conceptual de sua reflexão filosófica.

Sem quaisquer conclusões triunfalistas e nem se dando a otimismos fáceis, senão multiplicando advertências metodológicas e históricas ao leitor, o autor, no transcurso de sua longa exposição, não pode deixar de admitir, por força de sua própria pesquisa os êxitos obtidos pela filosofia no Brasil. 
O ufanismo a encobrir as nossas mazelas profundas com o brilho falso do paraíso tropical é um dos recursos, não resta dúvida, do arraigado conservadorismo de nossas elites e, por que não dizê-lo, de largos segmentos de nosso povo. O livro "Filosofia no Brasil" não envereda, de modo algum, neste conformismo fácil, mas antes, em seu final, constata com tristeza a continuidade do velho "padrão casa-grande E senzala" (p. 545). O inverso, porém, também não é sua praia, porque o catastrofismo, a desesperança apoiada em nosso caráter nacional irreformável não é menos conservador e nos leva a pensar que somos um povo perdido, uma nação ontologicamente corrupta e incapaz. Na extensa nota metodológica já citada, posta no início do último capítulo (p. 504), o autor, novamente inspirado por Weber e justificando o seu exercício conjectural nos convida a endossar " $a$ categoria de possibilidade objetiva, em vez de causalidade necessária, para pensar os fenômenos histórico-sociais" e, invocando a autoridade de Aristóteles reafirma a exigência "na questão dos futuros contingentes, de pensar o domínio da ação humana como aberto, no qual o que é pode não ser e o que não é pode ser".

Por que, então, recusar como questão fechada e já decidida a possibilidade de grandeza ou de relevância civilizacional para nossa vida econômica e social, para a nossa cultura intelectual e, especificamente, para a filosofia no Brasil? E onde o autor foi buscar a projeção prudencial de nossos legados senão em sua própria experiência? Não a do indivíduo isolado, pois este, como nos mostrou Freud, está sempre enredado em seu desamparo, mas sim a do observador participante e solidário nos trabalhos e nos dias do fazer filosófico. Foram dessas jornadas compridas e cumpridas, amanhando as terras por vezes ingratas das assessorias e viagens, orientações e reuniões, conversas frutíferas e leituras solitárias que foi possível tracejar, bem ao final do livro, o "tipo ideal do intelectual cosmopolita globalizado": ascético e crítico, engajado e descortinado.

A prospecção metafilosófica não consistiria em correr o risco de forcejar na dura realidade, em sua reiterada ingratidão, a ilusória alvíssara de um "possível aberto"? Não é, por outro lado, este o risco inerente a todo filosofar? Padre Henrique Vaz, em sua entrevista de 1997 aos Cadernos de Filosofia Alemã ao ser inquirido sobre as alternativas postas pelas relações do cristianismo com o mundo moderno responde hegelianamente: "o filósofo nunca profetiza, apenas analisa", resposta que obviamente não poderia escamotear a negatividade ínsita na positividade do presente. A filosofia, como ele ensinava insistentemente em suas aulas e em seus textos, se apresentou, desde sua aurora grega, com uma "face enigmática", justamente por buscar no afastamento do seu tópos, no êxodo do lugar comum de onde provinha a seiva de sua especulação, a força para o enfrentamento das aporias de sua origem e para resgatar as dores do seu nascimento. Sem que sua "vocação atópica", igualmente, anulasse a sua "feição aporética", pois a passagem do "tempo histórico" ao "lógico" ou, na definição célebre de Hegel, o compreender do tempo no pensamento, 
não elimina as aporias do seu ponto de partida e sim as transfigura sob uma nova luz, explorando outros horizontes para o pensamento e a ação.

O passado certamente nos pesa, a escravidão multissecular continua hipotecando a nossa república, se é que esta o foi algum dia, a pobreza endêmica, ainda mais vexatória e cruel porque modernizada, estigmatiza o presente gravoso como realidade verdadeiramente ingrata. Nada obstante, não fecha o futuro e nem nos leva a confundir o destino com um "cego acontecer". O filósofo não profetiza e nem pode trair a altivez crítica de seu pensamento. Porventura, a filosofia seria para nós uma "ideia fora do lugar"? Ao concluir a leitura do livro surpreendemos o intelectual do futuro já posto na grandeza do passado e prefigurado na genialidade de Machado de Assis. Ao citar Alfredo Bosi me lembrei de sua polêmica com Roberto Schwarz quando o grande estudioso de Machado oportunamente esclareceu a sua posição dialética: longe de ser um endosso ao nacionalismo conservador, o "fora do lugar" comportava uma "dupla inscrição". Denunciando a máscara liberal a dissimular a nossa bruta existência, também denunciava, por tabela, o discurso encobridor do humanismo esclarecido e disseminado pelo mundo desenvolvido e supostamente racional. A filosofia por toda parte é um "fora de lugar" produzindo inquietação e mal-estar nos lugares onde vivemos e devemos viver.

O livro do professor Ivan Domingues é muito bem-vindo. É obra de maturidade. Fruto colhido após trabalhoso cultivo. Não cala a esperança e aposta em nossos futuros possíveis. Destila a inquietação necessária. Sobretudo, nestes tempos tristes e trevosos nos quais vivemos e nos quais insistimos em crer e em trabalhar como se fossem tempos de transição e talvez o sejam! Assim seja. Oxalá!

Endereço do Autor:

Departamento de Filosofia

FAJE/BH

carlosdrawin@yahoo.com.br 